\title{
Feel isolated? Bridging communication between host myocardium and skeletal myoblast grafts
}

\author{
Zhi Cui, MSc, and Ren-Ke Li, MD, PhD
}

See related article on pages 348-56.

Therapies that decrease the risk of coronary heart disease are being actively researched. Of these, cell implantation is a cutting edge techniques that has attracted public attention. Established candidate cell types include embryonic stem cells, resident cardiac stem cells, mesenchymal stem cells, skeletal myoblasts, and endothelial progenitor cells. ${ }^{1}$ Skeletal myoblast transplantation in particular has progressed from the bench to clinical trials, and has been shown to be a safe and feasible treatment. Animal studies showed that grafted skeletal myoblasts can form contractile tissue ${ }^{2}$ and improve diastolic performance during the early stages after injury, with improvements in systolic function of the heart following at later stages. ${ }^{3}$ Positive results in these animal studies have advanced the use autologous skeletal myoblast implantation to the clinical trial stage. The first patients who received this treatment were reported by Menasché and colleagues ${ }^{4}$ in 2001, and no arrhythmias were found at 5 months after transplantation. Similar results were published in subsequent studies, reporting $3 \%$ to $20 \%$ improvement in ejection fraction after transplantation. ${ }^{5-8}$ Although myoblasts have many advantageous properties (contractility, ischemia resistance, and ease of obtaining autologous samples) and are excellent candidates for transplantation therapy, concerns were raised because of an increased incidence of sustained ventricular arrhythmia in later clinical trials, which predisposes patients to an increased risk of sudden cardiac death (Figure 1).9,10

Can we reduce the proarrhythmic effect of implanted skeletal myoblasts? The lack of electrical connection between implanted myoblasts and host cardiomyocytes causes dangerous arrhythmias and obstructs the use of these implants in a clinical setting. Cardiomyocytes express

\footnotetext{
From the Division of Cardiovascular Surgery, Toronto General Research Institute, University Health Network; and Department of Surgery, Division of Cardiac Surgery, University of Toronto, Toronto, Ontario, Canada.

Disclosures: Authors have nothing to disclose with regard to commercial support.

Received for publication Sept 22, 2014; accepted for publication Sept 27, 2014; available ahead of print Oct 22, 2014.

Address for reprints: Ren-Ke Li, MD, PhD, MaRS Centre, Toronto Medical Discovery Tower, Room 3-702, 101 College St, Toronto, Ontario, Canada, M5G 1L7 (E-mail: renkeli@uhnres.utoronto.ca).

J Thorac Cardiovasc Surg 2015;149:357-9

$0022-5223 / \$ 36.00$

Copyright (c) 2015 by The American Association for Thoracic Surgery http://dx.doi.org/10.1016/j.jtcvs.2014.09.110
}

connexin-43 $(\mathrm{Cx}-43)$, the gap junction protein that allows them to coordinate their activity, leading to a healthy heartbeat. $^{11}$ The absence of $\mathrm{Cx}-43$ makes skeletal myoblasts electrically isolated from neighboring cells and is a major hurdle limiting their clinical application for myocardial infarction. In this issue of the Journal of Thoracic and Cardiovascular Surgery, Treskes and colleagues ${ }^{12}$ present a method of reinvigorating $\mathrm{Cx}-43$ expression in skeletal myoblasts by applying a passive mechanical stretch to myoblast-based engineered tissue constructs. First, the authors used immunohistochemistry to demonstrate increased Cx-43 expression in both stretched grafted tissue and at its interface with host cardiomyocytes. Second, electrophysiologic experiments were conducted on viable cardiac tissue slices to record evoked action potential propagation. The lag between stimulation probe activation and recording probe excitation was shorter in stretched tissue compared with nonstretched tissue, indicating the presence of functional $\mathrm{Cx}-43$. The authors also assessed the coupling quality between grafted stretched tissue and host tissue in the presence of a $\mathrm{Cx}-43$ inhibitor. A conduction block was detected between grafted tissue and the host as the concentration of the gap junction inhibitor increased, indicating that the electrical propagation between the grafted tissue and the host was mediated by Cx-43.

The highlight of this article is that simple mechanical stretching can reduce skeletal myoblast implantationinduced arrhythmia by inducing Cx-43 expression, which bridges the communication gap between grafted tissue and host. Cyclic stretch can induce increased expression of Cx-43 in cardiomyocytes in vitro. ${ }^{13,14}$ Other techniques, such as lentiviral transduction, ${ }^{15}$ or $\mathrm{Cx}-43$ gene amplification via transfection, ${ }^{16}$ have also been used to express $\mathrm{CX}$ 43 in cardiomyocytes and have successfully enhanced electrical coupling with reduced occurrence of reentrant arrhythmia. However, the most simple method is always preferred. In addition, ventricular tachycardia, as a result of a heart attack, is caused by slow conduction at the scar tissue and border zone. ${ }^{17}$ The current treatment for ventricular tachycardia is surgical ablation to eliminate the abnormal conduction pathway without improvement in cardiac function. Cx43-expressing skeletal myoblasts have both a contractile phenotype and electrical coupling ability, which may benefit patients in future clinical studies. Furthermore, the cost of health care is a burden on families and society. Patients with congestive heart failure are currently treated with surgical implantation of a left ventricular-assist device 


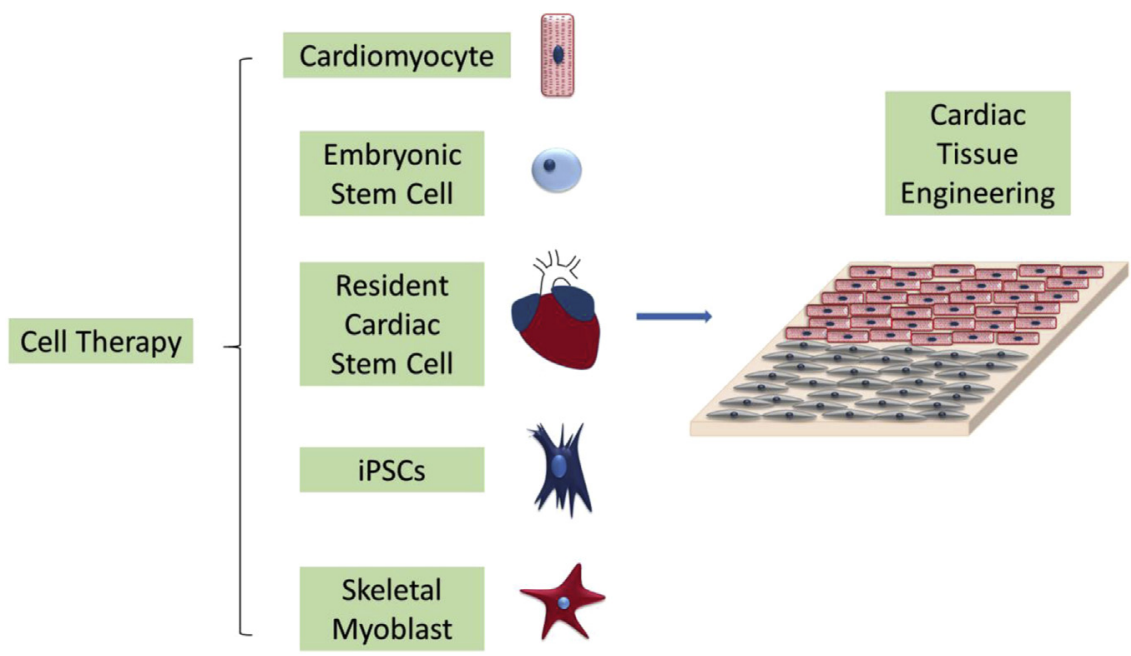

FIGURE 1. From cells to engineering tissue for cardiac repair. Various types of cells are under investigation with the goal of treating myocardial infarction. Cardiomyocytes are the ideal cell type for cardiac repair, because they can not only form contractible tissue but also electrically connect to each other and the host myocardium. Nevertheless, the survival of grafted cardiomyocytes remains low. Embryonic stem cells can proliferate without differentiation. After differentiation into cardiomyocytes, they have the same properties as adult cardiomyocytes. However, the use of embryonic stem cells in clinical applications is limited by ethical concerns. Resident cardiac stem cells found in the heart can differentiate into endothelial cells, smooth muscle cells, and cardiomyocytes. The application of resident cardiac stem cells is limited by their availability. Induced pluripotent stem cells (iPSCs) from fibroblasts can be driven to form cardiomyocytes using a viral vector. However, concerns about the risk of teratoma impede their use in clinical trials. Skeletal myoblasts have contractile phenotypes and are resistant to ischemia. The main limitation for the use of skeletal myoblasts is their lack of electrical coupling with the host myocardium. The expression of connexin-43 (Cx-43) in skeletal myoblasts bridges the implanted cell's initial communication with the host myocardium. The combination of these cells with biomaterials creates engineered tissue constructs that can be directly applied to host epicardium. The expression of $\mathrm{Cx}-43$ in skeletal myoblasts breaks the electrical wall and allows the implanted cells to begin communicating with the host myocardium.

to prolong their life. Stretched skeletal myoblast constructs may be inexpensive alternatives to treat ischemic/infarcted patients early after injury and slow down the progression toward heart failure.

Future investigations are required to optimize this work at the bench before it is ready for the clinic. First, how the cell biology of skeletal myoblasts is affected by mechanical stretch remains unclear. Expression/alteration of ion channels, adenosine triphosphate consumption, and $\mathrm{Ca}^{2+}$ handling in skeletal myoblasts should be investigated because the skeletal myotube experiences tetanic contraction and fatigue. Second, the mechanism of grafted tissue integration with the host myocardium needs to be addressed. In addition, synchronous coupling between stretched tissue and the host myocardium in a myocardial infarction model is required to confirm this result in a preclinical setting. Detailed optical mapping of the grafted tissue on the infarcted heart could directly visualize electrical propagation and activation time.

Overall, stretch-induced $\mathrm{Cx}-43$ expression in skeletal myoblasts for repairing infarcted hearts with a lower incidence of arrhythmia opens a new chapter in skeletal myoblast research. By demonstrating how mechanical stretching improves the success of skeletal myoblast transplantation, Treskes and colleagues ${ }^{12}$ have furthered our understanding of skeletal myoblast behavior and have contributed important information for future therapeutic development.

\section{References}

1. Zammaretti P, Jaconi M. Cardiac tissue engineering: regeneration of the wounded heart. Curr Opin Biotechnol. 2004;15:430-4.

2. Murry CE, Wiseman RW, Schwartz SM, Hauschka SD. Skeletal myoblast transplantation for repair of myocardial necrosis. J Clin Invest. 1996;98: 2512-23.

3. Atkins BZ, Hueman MT, Meuchel JM, Cottman MJ, Hutcheson KA, Taylor DA. Myogenic cell transplantation improves in vivo regional performance in infarcted rabbit myocardium. J Heart Lung Transplant. 1999;18:1173-80.

4. Menasché $\mathrm{P}$, Hagège AA, Scorsin M, Pouzet B, Desnos M, Duboc D, et al. Myoblast transplantation for heart failure. Lancet. 2001;357:279-80.

5. Herreros J, Prósper F, Perez A, Gavira JJ, Garcia-Velloso MJ, Barba J, et al. Autologous intramyocardial injection of cultured skeletal muscle-derived stem cells in patients with non-acute myocardial infarction. Eur Heart J. 2003;24: 2012-20.

6. Siminiak T, Fiszer D, Jerzykowska O, Grygielska B, Rozwadowska N, Kałmucki $\mathrm{P}$, et al. Percutaneous trans-coronary-venous transplantation of autologous skeletal myoblasts in the treatment of post-infarction myocardial contractility impairment: the POZNAN trial. Eur Heart J. 2005;26:1188-95.

7. Dib N, Michler RE, Pagani FD, Wright S, Kereiakes DJ, Lengerich R, et al. Safety and feasibility of autologous myoblast transplantation in patients with ischemic cardiomyopathy: four-year follow-up. Circulation. 2005;112: 1748-55.

8. Gavira JJ, Herreros J, Perez A, Garcia-Velloso MJ, Barba J, Martin-Herrero F, et al. Autologous skeletal myoblast transplantation in patients with nonacute myocardial infarction: 1-year follow-up. J Thorac Cardiovasc Surg. 2006;131: 799-804.

9. Fernandes S, Amirault JC, Lande G, Nguyen JM, Forest V, Bignolais O, et al. Autologous myoblast transplantation after myocardial infarction increases the inducibility of ventricular arrhythmias. Cardiovasc Res. 2006;69:348-58. 
10. Menasché P, Hagège AA, Vilquin JT, Desnos M, Abergel E, Pouzet B, et al. Autologous skeletal myoblast transplantation for severe postinfarction left ventricular dysfunction. J Am Coll Cardiol. 2003;41:1078-83.

11. Kanter HL, Saffitz JE, Beyer EC. Cardiac myocytes express multiple gap junction proteins. Circ Res. 1992;70:438-44.

12. Treskes P, Neef K. Srinivasan SP, Halbach M, Stamm C, Cowan D, et al. Preconditioning of skeletal myoblast-based engineered tissue constructs enables functional coupling to myocardium in vivo. J Thorac Cardiovasc Surg. 2015; 149:348-56.

13. Wang TL, Tseng YZ, Chang H. Regulation of connexin 43 gene expression by cyclical mechanical stretch in neonatal rat cardiomyocytes. Biochem Biophys Res Commun. 2000;267:551-7.
14. Salameh A, Wustmann A, Karl S, Blanke K, Apel D, Rojas-Gomez D, et al Cyclic mechanical stretch induces cardiomyocyte orientation and polarization of the gap junction protein connexin43. Circ Res. 2010;106:1592-602.

15. Abraham MR, Henrikson CA, Tung L, Chang MG, Aon M, Xue T, et al. Antiarrhythmic engineering of skeletal myoblasts for cardiac transplantation. Circ Res. 2005;97:159-67.

16. Suzuki K, Brand NJ, Allen S, Khan MA, Farrell AO, Murtuza B, et al Overexpression of connexin 43 in skeletal myoblasts: Relevance to cell transplantation to the heart. J Thorac Cardiovasc Surg. 2001;122:759-66.

17. Mehra R, Zeiler RH, Gough WB, El-Sherif N. Reentrant ventricular arrhythmias in the late myocardial infarction period. 9. Electrophysiologic-anatomic correlation of reentrant circuits. Circulation. 1983;67:11-24. 